\title{
Familial aggregation and heritability of asthma-associated quantitative traits in a population-based sample of nuclear families
}

\author{
Lyle J Palmer ${ }^{1,2,3}$, Paul R Burton ${ }^{1,4}$, Alan L James ${ }^{5}$, A William Musk ${ }^{6}$ and \\ William OCM Cookson ${ }^{7}$
}

\begin{abstract}
${ }^{1}$ Genetic Epidemiology Unit, Division of Population Sciences, TVW Telethon Institute for Child Health Research, Perth, Australia; ${ }^{2}$ Department of Epidemiology and Biostatistics, Case Western Reserve University, Cleveland, $\mathrm{OH}$; ${ }^{3}$ Channing Laboratory, Department of Medicine, Brigham and Women's Hospital and Harvard Medical School, Boston, MA, USA; ${ }^{4}$ Department of Epidemiology and Public Health, University of Leicester, Leicester, UK; ${ }^{5}$ Department of Pulmonary Physiology, Sir Charles Gairdner Hospital, Perth; ${ }^{6}$ University Department of Medicine and Department of Respiratory Medicine, Sir Charles Gairdner Hospital, Perth, Australia; ${ }^{7}$ Well come Trust Centre for Human Genetics, Nuffield Department of Clinical Medicine, John Radcliffe Hospital, Oxford, UK
\end{abstract}

Asthma is a common, genetically complex human disease. Elevated serum immunoglobulin E (IgE) levels, elevated blood eosinophil counts, variably reduced spirometric measures and increased airway responsiveness (AR) are physiological traits which are characteristic of asthma. We investigated the genetic and environmental components of variance of serum total and specific IgE levels, blood eosinophil counts, the forced expiratory volume in one second $\left(F^{2} V_{1}\right)$ and forced vital capacity (FVC), and AR in an Australian population-based sample of 232 Caucasian nuclear families. With the exception of FVC levels, all traits were closely associated with clinical asthma in this population. Log $_{e}$ total serum IgE levels had a narrow-sense heritability $\left(h_{N}^{2}\right)$ of $47.3 \%(S E=10.0 \%)$. Specific serum IgE levels against house dust mite and Timothy grass, measured as a RAST Index, had a $h_{N}^{2}$ of $33.8 \%$ (SE $=7.3 \%$ ). FEV ${ }_{1}$ levels had a $h_{N}^{2}$ of $6.1 \%$ (SE $=11.6 \%$ ), whilst FVC levels had a $h_{N}^{2}$ of $30.6 \%(S E=26.8 \%)$. AR, quantified by the $\log _{\mathrm{e}}$ dose-response slope to methacholine (DRS), had a $h_{N}^{2}$ of $30.3 \%$ (SE $=12.3 \%$ ). These data are consistent with the existence of important genetic determinants of the pathophysiological traits associated with asthma. Our study suggests that total and specific serum IgE levels, blood eosinophil counts and airways responsiveness to inhaled agonist are appropriate phenotypes for molecular investigations of the genetic susceptibility to asthma. European Journal of Human Genetics (2000) 8, 853-860.

Keywords: asthma; IgE; lung function; airway responsiveness; blood eosinophil count; genetics; variance components; Busselton Population Health Study

\section{Introduction}

Asthma is the most common chronic childhood disease in developed nations, and is associated with significant and increasing economic and social costs. ${ }^{1}$ Most asthma is closely associated with airway inflammation and narrowing. The familial syndrome of atopy (allergic asthma, seasonal rhinitis

Correspondence: Dr Lyle Palmer, The Channing Laboratory, Harvard Medical School, 181 Longwood Avenue, Boston MA 02115, USA. Tel: +1617525 0872; Fax: +16175250958; E-mail:

reljp@channing.harvard.edu

Received 1 March 2000; revised 3 July 2000; accepted 12 July 2000 and/or eczema) is accompanied by increased levels of total serum Immunoglobulin $\mathrm{E}$ (IgE) and elevated levels of IgE specific to common aero-allergens. ${ }^{2}$ In patients with asthma, specific serum IgE is most commonly detected against inhaled allergens from house dust mites (HDM) and grass pollens. ${ }^{3}$ Variably reduced spirometric measures such as the forced expiratory volume in one second $\left(\mathrm{FEV}_{1}\right)$ and the forced vital capacity (FVC) are closely but not specifically associated with asthma and atopy. ${ }^{4,5}$ Asthma is also typified by elevated blood eosinophil counts ${ }^{6}$ and by non-specific increased airway responsiveness (AR) to inhaled agonists 
such as histamine or methacholine, which can be quantified by measuring the reduction of expiratory airflow following increasing doses of these agents. ${ }^{7}$

Asthma is a genetically complex disease with poorly defined determinants. Considerable effort is currently being expended in the detection of genetic loci contributing to asthma susceptibility. ${ }^{8}$ Both binary disease status and asthma-associated quantitative phenotypic traits have been investigated. Power calculations suggest that testing for linkage is significantly enhanced by the use of quantitative traits in preference to a categorical asthma phenotype. ${ }^{9}$ The use of quantitative 'intermediate' phenotypes such as serum immunogl obulin E (IgE) levels or AR also permits selection of subjects for the extremes of distribution, with increased power to detect linkage. ${ }^{10}$ It is therefore important to examine the genetic basis of asthma-associated physiological traits.

The aim of this study was to use Variance Components Analysis to estimate the genetic and environmental components of variance of serum total and specific IgE levels, blood eosinophil counts, FEV ${ }_{1}, F V C$ and AR in a population-based sample of nuclear families. The relationship of these traits to physician-diagnosed asthma, age, gender, height, tobacco smoke exposure and the effects of length of cohabitation were also investigated.

\section{Methods \\ Study population}

Busselton is a rural town on the coast of South-Western Australia. In 1990 all residents on the Busselton electoral roll (approximately 9000 individuals) were sent a questionnaire regarding current respi ratory symptoms and medical history. From approximately 6500 replies, Caucasian families were ascertained for the present study. The study was undertaken during the winter months of May-July 1992, to avoid seasonal effects on the measured traits. Families with both parents alive and under 55 years of age and having at least two children over the age of 5 years were recruited serially. All individuals over the age of 5 years were studied, and complete data were obtained on 1020 subjects, comprising 232 nuclear families. The field methods used have been described in detail el sewhere; the response rate was $72 \%{ }^{11}$

The study was approved by the Human Rights Committee of the University of Western Australia, and informed personal or parental consent was obtained for all subjects.

\section{Questionnaire}

Individual and family histories of respiratory symptoms, demographic information and smoking were assessed at interview using the British Medical Research Council questionnaire. ${ }^{12}$ Questionnaires relating to children were administered to a parent, generally the mother. Pack years of smoking were calculated from questionnaire responses. One pack year was taken to be equivalent to the consumption of
20 cigarettes per day for 1 year. Physician-diagnosed asthma (ever) was defined as a positive response to the question 'Has your doctor ever told you that you have asthma/bronchial asthma?'

\section{IgE assays}

Total serum IgE titres and specific serum IgE titres to whole HDM (Dermatophagoides pteronyssinus) and Timothy grass pollen (Phleum pratense) were measured using the Immunocap FEIA (Pharmacia AB, Uppsala, Sweden). The titres of specific IgE were converted to RAST units according to Pharmacia recommendations. A 'combined RAST index' was calculated for each individual as the sum of the RAST scores to HDM and Timothy grass.

\section{Spirometry and airway responsiveness}

Spirometry was performed in the sitting position using a dry wedge spirometer (Vitalograph Model S, Maids Moreton, Buckinghamshire, UK) calibrated daily with a $3 \mathrm{~L}$ syringe. The best FEV ${ }_{1}$ and FVC were measured according to the guidelines of the American Thoracic Society. ${ }^{13}$ Spirometric data are expressed both as raw scores and as a percentage of predicted values, corrected for height, gender, age and race.

Height of subjects was measured at the time of spirometric assessment using a metric measuring tape.

Response to methacholine challenge was assessed by the Yan rapid method. ${ }^{14}$ The $\mathrm{FEV}_{1}$ was measured following inhalation of saline and increasing (doubling) doses of methacholine chloride delivered from calibrated hand-held nebulisers. At each dose, step one forced expiratory manoeuvre was performed unless it was thought to be technically unsatisfactory. The challenge was continued until either the $\mathrm{FEV}_{1}$ fell by at least $20 \%$ from the post-saline value or until the maximal cumulative dose ( $12 \mu \mathrm{mol}$ ) of methacholine was delivered. AR was expressed as the two-point dose-response slope (DRS) of methacholine response against percentage fail in $\mathrm{FEV}_{1}{ }^{15}$

\section{Eosinophil counts}

A full-blood picture was performed on each subject from whom blood was taken; this included an automated white cell count in order to establish a total blood eosinophil count.

\section{Statistical analysis}

The primary response variables modelled were:

(i) total serum IgE titre;

(ii) combined RAST index to house dust mite and Timothy grass;

(iii) peripheral blood eosinophil count;

(iv) $\mathrm{FEV}_{1}$;

(v) FVC; and 
(vi) the DRS to methacholine challenge.

Explanatory variables included gender, age, height, and pack years of smoking. In order to determine the relationship of asthma to the response variables independently of familial correlations and important covariates, physician diagnosed asthma was also included as an explanatory covariate in certain models.

All explanatory variables except gender and asthma status were analysed as continuous covariates. Total serum IgE levels, blood eosinophil counts and the DRS to methacholine exhibited a skewed distribution with a long right-hand tail; $\log _{\mathrm{e}}$-transformation rendered the marginal distributions of these variables approximately Normal. The combined RAST index also exhibited a skewed distribution with a long righthand tail; there was no obvious transformation to render the marginal distribution approximately Normal. Therefore, this variable was analysed in its raw form. A constant of 10 was added to each DRS and eosinophil measurement in order to allow $\log _{e}$ transformation when the value was $\leq 0$. FEV 1 and FVC levels were approximately Normally distributed and were analysed without transformation. All continuous covariates were centred at or close to their mean and were modelled as linear, quadratic and cubic fixed effects.

The software package FISHER $^{16}$ was used to partition observed phenotypic variance into genetic and non-genetic components by maximum likelihood methods. Each model assumed that the distribution of the response phenotype was multivariate normal, with a mean that depended on a particular set of explanatory covariates. The mean models and specification of variance and covariance structures are given in the Appendix. Analysis of the combined RAST index relied on tests of model fit to ensure that the skewed marginal distribution of this variable did not seriously distort assumptions of multivariate normality. It should be noted that marginal non-Normality need not necessarily imply lack of multivariate Normality once all the biological components of a model are included.

Phenotypic variance was partitioned into four components: $\sigma_{\mathrm{A}}^{2}=$ additive genetic effects; $\sigma_{\mathrm{CS}}^{2}=$ common sibling environment; $\sigma_{\mathrm{C}}^{2}=$ common family environment; and $\sigma_{\mathrm{EC}}^{2}$ or $\sigma_{\mathrm{EP}}^{2}=$ the residual variances (which are assumed to arise from non-familial factors) in children and in parents respectively.

The narrow-sense heritability $\left(h_{N}^{2}\right)$ was defined as the ratio of variance due to additive genetic effects $\left(\sigma_{A}^{2}\right)$ to the total phenotypic variance of each trait: ${ }^{17}$

$$
h_{N}^{2}=\sigma_{A}^{2} /\left(\sigma_{A}^{2}+\sigma^{2} C+\sigma_{C S}^{2}+\sigma_{E C}^{2}\right) \text {. }
$$

Asymptotic standard errors for $h_{N}^{2}$ were obtained by reparametrising the covariance model in terms of $h_{N}^{2}$ rather than $\sigma^{2}$.

The statistical associations of covariates entered as fixed effects and the current response variable were assessed by removal of terms from the mean model and calculation of a likelihood ratio $\chi^{2}$ test statistic. The same approach was used as an approximate guide to the 'significance' of a departure of the value of a variance component from its null value (zero). Statistical significance was taken as the $5 \%$ level.

Standard goodness-of-fit tests to check overall validity of model $s^{18}$ were performed using the FISHER program. ${ }^{16}$ These included a test of the acceptability of the assumption of multivariate Normality.

Cohabitation Length of cohabitation and the time living apart were adjusted for by modification of the $\sigma_{\mathrm{C}}^{2}$ parameter using exponential trends: ${ }^{19}$

$$
\begin{aligned}
\operatorname{Cov}\left(C_{i, j 1}, C_{i, j 2}\right) & =\sigma_{c}^{2}\left(1-e^{-\lambda t^{\prime}}\right) & & \text { if } t \leq t^{\prime} \\
& =\sigma_{c}^{2}\left(1-e^{-\lambda t^{\prime}}\right) e^{-v\left(t-t^{\prime}\right)} & & \text { if } t>t^{\prime}
\end{aligned}
$$

where: t represents the total possible time subjects $\mathrm{j} 1$ and $\mathrm{j} 2$ could have spent living together and $t$ ' represents the time subjects $j 1$ and $j 2$ have actually spent living together; $t-t^{\prime}$ thus measures the time $\mathrm{j} 1$ and $\mathrm{j} 2$ have spent living apart. ${ }^{19}$ The parameter $\lambda$ estimates the effect on $\sigma_{\mathrm{C}}^{2}$ attributable to time spent cohabiting, and $v$ estimates the effect on $\sigma_{\mathrm{C}}^{2}$ attributable to time spent living apart.

As precise durations of cohabitation were not available from the data collected, it was necessary to make the following assumptions. Children less than the age of 18 years were assumed to have cohabited continuously with parents for a length of time equivalent to their age; children less than the age of 18 years were assumed to have cohabited continuously with their siblings for a length of time equivalent to the age of the younger sibling; children were assumed to cease cohabiting with other family members at age 18; adults were assumed to have cohabited continuously with their spouse for a length of time equivalent to the age of their oldest child.

\section{Results}

\section{Characteristics of families}

The mean number of children per family was 2.35. Males and females were equally represented in the study population (Table1). The mean age $( \pm S D)$ of parents was $40.2 \pm 5.0$ years and of children $12.6 \pm 4.7$ years.

\section{Effects of age, gender, pack years of smoking and height} The variance components modelling suggested that the joint age and gender effect (see mean model specification in the Appendix) was significant for total serum $\operatorname{IgE}\left(\chi_{7}^{2}=68.9\right.$, $P<0.0001)$, the combined RAST index $\left(\chi_{7}^{2}=44.7\right.$, $P<0.0001)$, eosinophil levels $\left(\chi_{7}^{2}=17.8, P=0.01\right)$, and DRS levels $\left(\chi_{7}^{2}=39.1, P<0.0001\right)$. Levels were higher in males and in children (Table 1). Neither pack years of smoking nor height were significantly related to total IgE levels, the RAST index or eosinophil level. There was some evidence of an association between increased height and increased $A R$, although the relationship was not formally significant 
$\left(\chi_{3}^{2}=7.2, P=0.07\right)$. Pack years of smoking were not significantly related to the DRS.

The joint age and gender effect was highly significant for FEV $_{1}\left(\chi_{7}^{2}=132.7, P<0.0001\right)$ and FVC levels $\left(\chi_{7}^{2}=219.5\right.$, $\mathrm{P}<0.0001)$. Although $\mathrm{FEV}_{1}$ and FVC levels were similar in male and females (Table1), there was a steeper increase or decline with age in male children or adults respectively (data not shown). Linear and quadratic terms for height were closely associated with both $\mathrm{FEV}_{1}\left(\chi_{2}^{2}=311.0, \mathrm{P}<0.0001\right)$ and FVC $\left(\chi_{2}^{2}=600.0, \mathrm{P}<0.0001\right)$ levels; the pattern of the effect was similar to the effects of age in both genders. Linear and quadratic terms for pack years of smoking were inversely associated with $\mathrm{FEV}_{1}\left(\chi_{2}^{2}=9.9, \mathrm{P}=0.007\right)$ and $\mathrm{FVC}\left(\chi_{2}^{2}=24.6\right.$, $P<0.0001$ ) levels.

\section{Associations with asthma}

The variance components modeling indicated that increased total $\left(\chi_{1}^{2}=69.1, \quad P<0.0001\right)$ and specific $\left(\chi_{1}^{2}=88.4\right.$, $P<0.0001)$ serum IgE levels were closely associated with the presence of physician-diagnosed asthma (ever). Increased blood eosinophil counts $\left(\chi_{1}^{2}=26.1, P<0.0001\right)$, decreased FEV $_{1}$ levels $\left(\chi_{1}^{2}=9.9, P=0.002\right)$, and increased DRS to methacholine $\left(\chi_{1}^{2}=164.0, \quad P<0.0001\right)$ were also closely associated with asthma. FVC level was not significantly associated with asthma $\left(\chi_{1}^{2}=1.3, P=0.4\right)$. These associations were independent of age, gender, pack years of smoking, and height, and the covariance model ensured appropriate adjustment for familial correlation.

\section{Variance components and heritability estimates}

After adjustment for all covariates, the $h_{\mathrm{N}}^{2}$ of serum total IgE levels was $47.3 \%$ (SE $=10.0 \%$ ), ie additive genetic effects $\left(\sigma_{A}^{2}\right)$ contributed just under half of the total variance (Table2). $\sigma_{A}^{2}$ was significantly greater than zero $\left(\chi_{1}^{2}=20.5, \mathrm{P}<0.0001\right)$. Familial environmental effects were not significantly different from zero (Table2).

The $h_{N}^{2}$ of the RAST index was estimated to be $28.9 \%$ (SE $=7.4 \%$ ) (Table2). $\sigma_{\mathrm{A}}^{2}$ was significantly greater than zero $\left(\chi_{1}^{2}=17.5, \mathrm{P}<0.0001\right)$. Environmental effects common to siblings $\left(\sigma_{\mathrm{CS}}^{2}\right)$ were also significantly greater than zero $\left(\chi_{1}^{2}=11.4, \mathrm{P}=0.001\right)$ and contributed approximately $15 \%$ of the total phenotypic variance. Environmental effects common to families $\left(\sigma_{\mathrm{C}}^{2}\right)$ were not significantly different from zero and contributed only minimally, if at all, to total phenotypic variance (Table2).

The $h_{N}^{2}$ of eosinophil counts was estimated to be $29.8 \%$ (SE $=9.6 \%$ ) (Table2). $\sigma_{\mathrm{A}}^{2}$ was significantly greater than zero $\left(\chi_{1}^{2}=8.7, \mathrm{P}=0.003\right)$. Familial environmental effects were not significantly different from zero (Table2).

Table 1 Population characteristics, mean (SD)

\begin{tabular}{|c|c|c|c|c|}
\hline & $\begin{array}{l}\text { Mothers } \\
(n=232)\end{array}$ & $\begin{array}{l}\text { Fathers } \\
(n=232)\end{array}$ & $\begin{array}{l}\text { Female offspring } \\
(n=278)\end{array}$ & $\begin{array}{l}\text { Male offspring } \\
(\mathrm{n}=278)\end{array}$ \\
\hline Age (years) & $38.9(4.8)$ & $41.5(4.8)$ & $12.7(4.9)$ & $12.6(4.6)$ \\
\hline Height $(\mathrm{cm})$ & $164.0(6.2)$ & $176.3(7.6)$ & 149.9 (17.0) & $153.0(20.8)$ \\
\hline Total serum IGe & 25.7 & 40.4 & 62.1 & 73.7 \\
\hline (IU/ml) & $(20.7$ to 32.0$)$ & (32.8 to 46.6$)$ & (50.5 to 76.5$)$ & (60.3 to 88.8$)$ \\
\hline RAST index & $1.7(2.4)$ & $1.8(2.2)$ & $2.3(3.1)$ & $2.8(2.9)$ \\
\hline Eosinophil count $^{a}$ & 191.1 & 191.2 & 220.3 & 255.3 \\
\hline $\mathrm{FEV}_{1}(\mathrm{~L})$ & $2.8(0.4)$ & $3.7(0.6)$ & $2.3(0.9)$ & $2.6(1.1)$ \\
\hline $\mathrm{FEV}_{1}$ (\% predicted) & $97.1(12.5)$ & $92.4(21.5)$ & $93.7(11.4)$ & $91.9(12.8)$ \\
\hline FVC (L) & $3.4(0.5)$ & $4.6(0.7)$ & $2.6(0.9)$ & $3.0(1.4)$ \\
\hline FVC (\% predicted) & $100.3(12.4)$ & $95.5(23.0)$ & $92.1(11.2)$ & $92.8(11.6)$ \\
\hline DRS to methacholine ${ }^{a}$ & 1.8 & 2.2 & 2.7 & 3.7 \\
\hline (\% fall in $\mathrm{FEV}_{1}$ per $\mu \mathrm{mol}$ methacholine) & (1.4 to 2.3$)$ & (1.7 to 2.7 ) & $(2.2$ to 3.4$)$ & (2.9 to 4.7$)$ \\
\hline Pack years of smoking & $3.1(7.8)$ & $9.1(13.5)$ & $0.2(1.0)$ & $0.2(1.4)$ \\
\hline Asthma (ever) \% (n) & $16.4(38)$ & $15.5(36)$ & $20.5(57)$ & $27.0(75)$ \\
\hline
\end{tabular}

aGeometric mean and 95\% confidence intervals ( $+1.96 \mathrm{SEM})$.

bPositive answer to the question: 'Has your doctor ever told you that you have asthma or bronchial asthma?'

Table 2 Maximum likelihood model ${ }^{\mathrm{a}}$ showing variance components estimates

\begin{tabular}{llllll}
\hline Outcome variable & $\sigma_{\mathrm{A}}^{2}(\mathrm{SE})$ & $\sigma_{\mathrm{C}}^{2}(\mathrm{SE})$ & $\sigma_{\mathrm{CS}}^{2}(\mathrm{SE})$ & $\sigma_{\mathrm{EC}}^{2}(\mathrm{SE})$ & $\sigma_{\mathrm{EP}}(\mathrm{SE})$ \\
\hline Log $_{\mathrm{e}}$ total serum IgE level & $1.319(0.282)$ & $0.047(0.154)$ & $0.186(0.148)$ & $1.236(0.215)$ & $0.736(0.254)$ \\
Combined RAST index & $2.983(0.677)$ & $0.247(0.341)$ & $1.365(0.462)$ & $4.233(0.570)$ & $0.702(0.314)$ \\
Log $_{\mathrm{e}}$ eosinophil level & $0.164(0.054)$ & $0.006(0.027)$ & $0.056(0.032)$ & $0.324(0.044)$ & $0.160(0.051)$ \\
FEV $_{1}$ & $0.013(0.025)$ & $0.027(0.013)$ & 0.000 & $0.175(0.020)$ & $0.150(0.024)$ \\
FVC & $0.035(0.031)$ & $0.022(0.016)$ & 0.000 & $0.058(0.016)$ & $0.191(0.022)$ \\
Log $_{\mathrm{e}}$ DRS level & $1.100(0.458)$ & $0.262(0.244)$ & $0.150(0.207)$ & $2.156(0.318)$ & $2.121(0.400)$ \\
\hline
\end{tabular}

a Model adjusted for age, sex, pack years of smoking and height. 
The $h_{N}^{2}$ of $\mathrm{FEV}_{1}$ levels was estimated to be $6.1 \%$ (SE $=11.6 \%$ ) (Table2); $\sigma_{\mathrm{A}}^{2}$ was not significantly greater than zero $\left(\chi_{1}^{2}=0.3, P=0.6\right)$. $\sigma_{C}^{2}$ was significantly greater than zero $\left(\chi_{1}^{2}=4.5, \mathrm{P}=0.04\right)$. The contribution of $\sigma_{\text {CS }}^{2}$ to phenotypic variance was estimated to be zero (Table2).

The $h_{N}^{2}$ of FVC levels was estimated to be $30.6 \%$ (SE $=26.8 \%$ ) (Table2). Despite this potentially large effect, $\sigma_{\mathrm{A}}^{2}$ was not significantly greater than zero $\left(\chi_{1}^{2}=1.3, P=0.2\right) . \sigma_{C}^{2}$ was not significantly greater than zero $\left(\chi_{1}^{2}=1.9, p=0.07\right)$. The contribution of $\sigma_{\mathrm{CS}}^{2}$ to phenotypic variance was estimated to be zero (Table2).

The $h_{N}^{2}$ of DRS levels was estimated to be $30.0 \%$ (SE $=12.3 \%$ ) (Table2). $\sigma_{\mathrm{A}}^{2}$ was significantly greater than zero $\left(\chi_{1}^{2}=5.5, P=0.02\right)$. Familial environmental effects were not significantly different from zero and contributed only minimally, if at all, to total phenotypic variance (Table2).

The goodness-of-fit tests did not indicate any significant lack-of-fit problems for any of the models reported.

\section{Cohabitation effects}

Extended modelling including terms for time spent living together and apart indicated that duration and cessation of cohabitation had no discernable effect upon the model for either total serum IgE levels $\left(\chi_{2}^{2}=0.5, P=0.2\right)$ or the combined RAST index $\left(\chi_{2}^{2}=0.3, P=0.8\right)$. Similarly, extended modelling of DRS to methacholine $\left(\chi_{2}^{2}=0.7, P=0.7\right)$, eosinophil levels $\left(\chi_{2}^{2}=0.9, P=0.6\right), \mathrm{FEV}_{1}$ levels $\left(\chi_{2}^{2}=4.3, \mathrm{P}=0.1\right)$ and FVC $\left(\chi_{2}^{2}=2.3, P=0.3\right)$ level s suggested little or no effect of cohabitation.

While not significant, the relative magnitudes of the estimates of $\lambda$ and $v$ were similar for all outcomes: $\lambda$ was large relative to $v$. As an illustration, the effects of $\lambda$ and $v$ on $\sigma_{C}^{2}$ for total serum IgE were plotted using the original equations and assumptions (Figure1). The correlation in total serum IgE levels amongst family members due to cohabitation has almost immediate consequences on commencement of cohabitation. The correlation due to shared environment

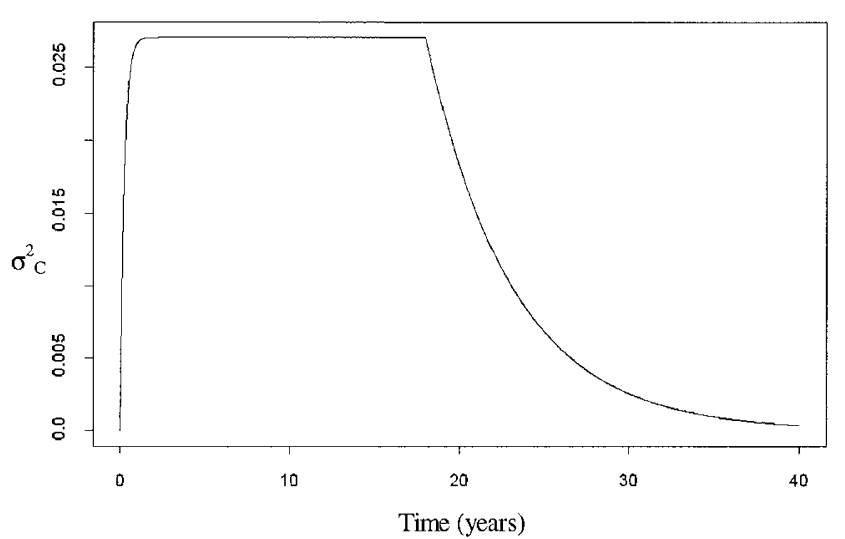

Figure 1 Effects of cohabitation and cessation of cohabitation upon familial correlations $\left(\sigma_{\mathrm{C}}^{2}\right)$ in total serum IgE levels ( $\mathrm{t}^{\prime}=18$ years). continues until the subjects cease cohabiting, and declines thereafter. A similar pattern was observed for specific serum $\operatorname{lgE}, \mathrm{FEV}_{1}, \mathrm{FVC}$ and the DRS.

\section{Discussion}

Our study was designed to recruit a sample of families which were representative of a general Caucasian population, and has shown that the total serum IgE, specific IgE titres to common allergens, blood eosinophil counts and AR are strongly heritable traits.

The prevalence rates for self-reported asth ma for adults and children in the study were similar to those found in other Australian population studies. ${ }^{20,21}$ As other investigations have reported, ${ }^{22}$ asthma was more common in boys than girls. The close associations of all the outcomes investigated with physician-diagnosed asthma were consistent with previous studies. ${ }^{2,3,5-7}$ The relationship of the outcomes investigated to age and gender was similar to that found in other population-based studies of Caucasians. ${ }^{23-28}$ The smoking rates for parents and offspring were similar to those in the Australian general population. 29,30

Our analysis of cohabitation did not suggest any important effects on the $\sigma_{\mathrm{C}}^{2}$ estimates due to duration of cohabitation. Although this analysis included a number of strong assumptions, it is unlikely that major duration of cohabitation effects existed if our analysis failed to detect any suggestion of such effects.

The importance of familial determinants in the regulation of serum IgE production in humans is well established. ${ }^{31}$ Studies of pedigrees and twins have suggested that total serum IgE levels have a heritability of around $50-80 \%,{ }^{23,32-34}$ consistent with the present results. Our study further shows the correlations to be independent of the effects of age, gender, height or total pack years of cigarette consumption. Most of the observed familial correlations are attributable to genetic rather than environmental factors. The relative contributions of familial and non-familial environmental factors to variance in total serum IgE levels are consistent with those reported in other studies. ${ }^{34,35}$

The heritability of specific serum IgE levels has not previously received much attention, ${ }^{33}$ and it is of interest that our results show strong genetic effects underlying this trait. The significant contribution (15\%) of common sibling environment to this trait is consistent with the effects of childhood exposure to domestic allergens on specific IgE responses. Despite the marginal non-Normality of the RAST index, the models we present pass standard tests of multivariate Normality at the $5 \%$ significance level. Furthermore, inferences were unaffected if modelling was based on the t-distribution instead of the Normal distribution.

While there is evidence of significant familial aggregation of blood eosinophil counts from studies of endemically parasitised populations, ${ }^{36}$ there is sparse evidence in nonparasitised human populations. A recent population-based 
study of Caucasian families from Tuscon, Arizona, found evidence of substantial familial aggregation in peripheral blood eosinophil counts. ${ }^{37}$ That study was consistent with our results, which also suggests substantial correlations in peripheral blood eosinophil counts between genetically related individuals that are independent of the effects of age, gender, height or cumulative active smoking exposure. Most of the observed familial correlations are consistent with genetic rather than environmental factors.

Both pedigree- and twin-based studies give consistent evidence of a genetic contribution to the variability of spirometric indices. ${ }^{38-41}$ However, estimates of the broadsense heritabilities of $\mathrm{FEV}_{1}$ and FVC derived from twin studies which have adjusted for body size have ranged from $0 \%$ to around $75 \%$. In agreement with a previous twin study reporting the heritability of $\mathrm{FEV}_{1}$ levels to be close to zero, ${ }^{42}$ our results suggest only small correlations in $\mathrm{FEV}_{1}$ levels between genetically related individuals after adjustment for height, age, gender and tobacco smoke exposure. In contrast to $\mathrm{FEV}_{1}$, substantial correlations in FVC levels between genetically related individuals were found. These results are consistent with previous studies of FVC levels. ${ }^{39,41}$ The majority of the observed familial correlations in FVC appear to be due to the effects of additive genetic factors transmitted from parents to offspring. However, the confidence limits on the $\sigma_{\mathrm{A}}^{2}$ estimate were large (Table2) and the $\sigma_{\mathrm{A}}^{2}$ estimate was not significantly different from zero; these data are therefore consistent with both a small and a large additive genetic component of total variance.

Few studies have directly estimated the heritability or mode of inheritance of AR in humans. One study, of $61 \mathrm{MZ}$ and $46 \mathrm{DZ}$ twin-pairs aged 6 to 31 years, ${ }^{32}$ estimated the broad-sense heritability of the area under the $\log _{\mathrm{e}}$ methacholine dose-response curve as approximately $66 \%$. This is consistent with our findings of substantial familial correlations in AR that were independent of the effects of age, gender, height, or smoking. The majority of the observed familial correlations in DRS were due to genetic factors transmitted from parents to offspring, with a minor contribution from environmental factors common to families.

The present study suggests the presence of important genetic determinants of the pathophysiological traits associated with asthma and that total and specific serum IgE levels, blood eosinophil counts and airways responsiveness to inhaled agonist are appropriate phenotypes for molecular investigations of the genetic susceptibility to asthma. In extended analyses, we have investigated the overlap between the genetic determinants $\left(\sigma_{A}^{2}\right)$ of these correlated quantitative traits in the Busselton study population. ${ }^{9,43}$ With the exception of total and specific serum IgE levels, which exhibited around a $50 \%$ overlap in genetic determinants, there was little evidence of shared genetic determinants influencing these traits, ie these data suggested that serum IgE levels, blood eosinophil counts, and airways responsiveness are genetical ly distinct traits. These extended analyses will be the subject of further manuscripts.

The results of this study also suggest that FVC, while possibly under substantial genetic control, is not associated with asthma after adjustment for sex, age, height, tobacco smoke exposure and familial correlation, and therefore may not be a useful phenotype for investigations of the gen etics of asthma.

Whole genome screens investigating linkage of asthma and associated phenotypes are consistent with the results of this study; significant linkage to serum IgE levels, blood eosinophil counts and/or AR has been found in the majority of gen ome screens. ${ }^{44-52}$ One of these whole genome screens was based on a subset of the population described in this paper. ${ }^{44}$ In that study, $\log _{\mathrm{e}}$ total serum IgE levels, the RAST index, $\log _{\mathrm{e}}$ eosinophil count and $\log _{\mathrm{e}}$ DRS showed significant linkage to different chromosomes. The specific genes responsible for the heritibilities of serum IgE levels, blood eosinophil counts, FVC and AR remain to be defined, as do their interrelationships with environmental factors.

\section{Acknowledgements}

We thank the people of the Busselton community for their participation in this study and the many colleagues who assisted in the collection of this data. W OCMC is a WellcomeSenior Clinical Research Fellow; LJP is a National Health \& Medical Research Council of Australia Postdoctoral Fellow in Genetic Epidemiology, a Winston Churchill Trust Churchill Fellow and an Australian-American Educational Foundation Fulbright Fellow. This study was supported by the Wellcome Trust (UK) and the National Health and Medical Research Council of Australia.

\section{References}

1 The International Study of Asthma and Allergies in Childhood (ISAAC) Steering Committee: Worldwide variation in prevalence of symptoms of asthma, allergic rhinoconjunctivitis, and atopic eczema: ISAAC. Lancet 1998; 351: 1225-1232.

2 Burrows B, Martinez $F$, Halonen $M$ et al: Association of asthma with serum IgE levels and skin-test reactivity to allergens. N Engl J Med 1989; 320: 271-277.

3 Sears M, Herbison G, Holdaway $M$ et al: The relative risks of sensitivity to grass pollen, house dust mite and cat dander in the development of childhood asthma. Clin Exp Allergy 1989; 19: 419-424.

4 Enright PL, Lebowitz MD, Cockroft DW: Physiologic measures: pulmonary function tests. Asthma outcome. Am J Respir Crit Care Med 1994; 149: S9-18 discussion S19-20.

5 Sherrill DL, Lebowitz MD, Halonen $M$ et al: Longitudinal evaluation of the association between pulmonary function and total serum IgE. Am J Respir Crit Care Med 1995; 152: 98-102.

6 Bousquet J, Chanez P, Vignola AM et al: Eosinophil inflammation in asthma. Am J Respir Crit Care Med 1994; 150: S33-38.

7 Ryan G, Latimer K, Dolovich J et al: Bronchial responsiveness to histamine: relationship to diurnal variation of peak flow rate, improvement after bronchodilator, and airways calibre. Thorax 1982; 37: 423-429.

8 Moffatt MF, Cookson WO: Gene identification in asthma and allergy. Int Arch Allergy Immunol 1998; 116: 247-252.

9 Cookson W, Palmer L: Investigating the asthma phenotype. Clin Exp Allergy 1998; 28: 88-89. 
10 Risch N, Merikangas K: The future of genetic studies of complex human diseases. Science 1996; 273: 1516-1517.

11 Hill M, James A, Faux J et al: FceRI- $\beta$ polymorphism and risk of atopy in a general population sample. $\mathrm{Br}$ Med J 1995; 311: 776-779.

12 Medical Research Council Committee on the Aetiology of Chronic Bronchitis (MRC): Definition and classification of chronic bronchitis for clinical and epidemiological purposes. Lancet 1965; 1: 775-779.

13 American Thoracic Society (ATS): Standardisation of spirometry, 1994 update. Am J Respir Crit Care Med 1995; 152: 1107-1136.

14 Yan K, Salome C, Woolcock A: Rapid method for measurement of bronchial responsiveness. Thorax 1983; 38: 760-765.

15 O'Connor G, Sparrow D, Taylor D et al: Analysis of dose-response curves to methacholine: an approach suitable to population studies. Am Rev Respir Dis 1987; 136: 1412-1417.

16 Lange K, Weeks D, Boehnke M: Programs for pedigree analysis: MENDEL, FISHER and dGENE. Genet Epidemiol 1988; 5: 471-472.

17 Khoury M, Beaty T, Cohen B: Fundamentals of Genetic Epidemiology. Oxford University Press: Oxford, 1993.

18 Hopper J, Matthews J: A multivariate normal model for pedigree and longitudinal data and the software FISHER. Aust J Statistics 1994; 36: 153-176.

19 Hopper JL: Variance components for statistical genetics: applications in medical research to characteristics related to human diseases and health. Stat Methods Med Res 1993; 2: 199-223.

20 Hopper J, Jenkins M, Carlin J et al: Increase in the self-reported prevalence of asthma and hay fever in adults over the last generation: a matched parent-offspring study. Aust J Public Health 1995; 19: 120-124.

21 Crockett AJ, Cranston JM, Alpers JH: The changing prevalence of asthma-like respiratory symptoms in South Australian rural schoolchildren. J Paediatr Child Health 1995; 31: 213-217.

22 Clough JB: The effect of gender on the prevalence of atopy and asthma [editorial]. Clin Exp Allergy 1993; 23: 883-885.

23 Grundbacher FJ: Causes of variation in serum IgE levels in normal populations. J Allergy Clin Immunol 1975; 56: 104-111.

24 Barbee R, Halonen M, Lebowitz M et al: Distribution of IgE in a community population sample: correlations with age, sex, and allergen skin test reactivity. J Allergy Clin Immunol 1981; 68: 106-111.

25 Cunningham A: Eosinophil counts: age and sex differences. J Pediatr 1975; 87: 426-427.

26 McGrath C, Hitchcock D, vanAssendelft O: Total white blood cell counts for adult ages 25-74 years: United States, 1971-75. Vital Health Stat 1982; 11: 1-36.

27 Cotes ]: Lung Function: Assessment and Application in Medicine, 5th edn. Blackwell Scientific Publications: Oxford, 1993.

28 Paoletti F, Carrozzi L, Viegi G et al: Distribution of bronchial responsiveness in a general population: effect of sex, age, smoking, and level of pulmonary function. Am J Respir Crit Care Med 1995; 151: 1770-1777.

29 Hill D, White V, Williams R et al: Tobacco and alcohol use among Australian secondary school students in 1993. Med J Aust 1993; 158: 228-234.

30 Hill D, White V: Australian adult smoking prevalence in 1992. Aust J Public Health 1995; 19: 305-308.

31 Gerrard J, Rao D, Morton N: A genetic study of Immunoglobulin E. Am J Hum Genet 1978; 30: 46-58.

32 Hopp R, Bewtra A, Watt $G$ et al: Genetic analysis of allergic disease in twins. J Allergy Clin Immunol 1984; 73: 265-270.

33 Blumenthal $M$, Bonini S: Immunogenetics of specific immune responses to allergens in twins and families. In: Marsh $D$, Blumenthal M (eds), Genetic and Environmental Factors in Clinical Allergy. University of Minneapolis Press: Minneapolis, 1990; pp 132-142.

34 Hanson B, McGue M, Roitman-Johnson B et al: Atopic disease and immunoglobulin $\mathrm{E}$ in twins reared apart and together. Am J Hum Genet 1991; 48: 873-879.
35 Wuthrich B, Baumann E, Fries R et al: Total and specific IgE (RAST) in atopic twins. Clin Allergy 1981; 11: 147-154.

36 Moro-Furlani A, Krieger $\mathrm{H}$ : Familial analysis of eosinophilia caused by helminthic parasites. Genet Epidemiol 1992; 9: 185-190.

37 Holberg CJ, Halonen M, Wright AL et al: Familial aggregation and segregation analysis of eosinophil levels. Am J Respir Crit Care Med 1999; 160: 1604-1610.

38 Beaty T, Liang K, Seerey $\mathrm{S}$ et al: Robust inference for variance components models in families ascertained through probands: II. Analysis of spirometric measures. Genet Epidemiol 1987; 4: 211-221.

39 Redline S, Tishler P, Lewitter $\mathrm{F}$ et al: Assessment of genetic and nongenetic influences on pulmonary function. A twin study. Am Rev Respir Dis 1987; 135: 217-222.

40 Cotch M, Beaty T, Cohen B: Path analysis of familial resemblance of pulmonary function and cigarette smoking. Am Rev Respir Dis 1990; 142: 1337-1343.

41 McClearn G, Svartengren M, Pedersen N et al: Genetic and environmental influences on pulmonary function in aging Swedish twins. J Gerontol 1994; 49: 264-268.

42 Del Prete GF, De Carli M, D'Elios MM et al: Allergen exposure induces the activation of allergen-specific Th2 cells in the airway mucosa of patients with allergic respiratory disorders. Eur J Immunol 1993; 23: 1445-1449.

43 Palmer LJ: The genetic epidemiology of asthma: An investigation of a complex human disease. PhD Thesis, Department of Paediatrics, University of Western Australia, Perth, 1998.

44 Daniels S, Bhattacharrya S, James A et al: A genome-wide search for quantitative trait loci underlying asthma. Nature 1996; 383 247-250.

45 CSGA: A genome-wide search for asthma susceptibility loci in ethnically diverse populations. Nat Genet 1997; 15: 389-392.

46 Ober C, Cox NJ, Abney M et al: Genome-wide search for asthma susceptibility loci in a founder population. The Collaborative Study on the Genetics of Asthma. Hum Mol Genet 1998; 7: 1393-1398.

$47 \operatorname{Cox}$ N, Beaty T, Rich S et al: Genome screen for asthma susceptibility loci in US populations. Am J Respir Crit Care Med 1998; 157: A855.

48 Ober C, Tsalenko A, Willadsen S et al: Genome-wide screen for atopy susceptibility alleles in the Hutterites. Clin Exp Allergy 1999; 29(Suppl 4): 11-15.

49 Dizier MH, Matran R, Meunier F et al: Genome screen for asthma and related phenotypes in the french EGEA study. Am J Respir Crit Care Med 1999; 159: A649.

50 Wjst $M$, Fischer $G$, Immervoll $T$ et al: A genome-wide search for linkage to asthma. Genomics 1999; 58: 1-8.

51 Bleecker ER, Postma DS, Howard TD et al: Genome screen for susceptibility loci for bronchial hyperresponsiveness in a genetically homogeneous Dutch population. Am J Respir Crit Care Med 1999; 159: A645.

52 Wjst M: Specific IgE-one gene fits all? German Asthma Genetics Group. Clin Exp Allergy 1999; 29(Suppl 4): 5-10. 


\section{Appendix}

1 The mean models were specified as follows:

Mean $=\beta_{1}+\delta .\left(\beta_{2}+\beta 3\right.$.age $+\beta_{4}$.age ${ }^{2}+\beta_{5}$.age $)+\beta_{10}$. (cigarette pack years $)^{2}+\beta_{11}$. (cigarette pack years) ${ }^{3}+\beta_{12}$. height + $\beta_{13}$.height ${ }^{2}+\beta_{14}$. height ${ }^{3}$;

where: $\beta_{n}$ was the $n^{\text {th }}$ fixed regression coefficient and $\delta$ is a binary indicator variable taking the value 1 in males and 0 in females. This model permitted independent age-specific profiles for the phenotype of interest in males and females.

2 The total phenotypic variance (conditional on the mean model) was based on a conventional covariance structure ${ }^{17}$ and was specified as:

$$
\left(\sigma^{2}\right)=\sigma_{\mathrm{A}}^{2}+\sigma_{\mathrm{CS}}^{2}+\sigma_{\mathrm{C}}^{2}+\gamma \cdot \sigma_{\mathrm{EC}}^{2}+(1-\gamma) \cdot \sigma_{\mathrm{EP}}^{2}
$$

The residual variance was al lowed to differ between children and parents; the binary indicator variable $\gamma$ took the value 1 in children and 0 in parents.

3 The conditional covariances within a family were specified as:
(i) $\frac{1}{2} \sigma_{\mathrm{A}}^{2}+\sigma_{\mathrm{CS}}^{2}+\sigma_{\mathrm{C}}^{2}$ between two siblings;
(ii) $\frac{1}{2} \sigma_{\mathrm{A}}^{2}+\sigma_{\mathrm{C}}^{2}$ between a parent and a child; and
(iii) $\sigma_{\mathrm{C}}^{2}$ between two parents. 